\title{
ESTADO DEMOCRÁTICO DE DIREITO E PUNIÇÃO: Reflexões sobre os \\ princípios reitores do Direito Penal
}

Prof. Dr. Claudio Alberto Gabriel Guimarães, Lícia Haickel Rosa

\section{UNIVERSIDADE CEUMA}




\title{
ESTADO DEMOCRÁTICO DE DIREITO E PUNIÇÃO: Reflexões sobre os princípios reitores do Direito Penal
}

\author{
DEMOCRATIC STATE OF LAW AND PUNISHMENT : \\ Reflections on the rectors principles of criminal law
}

\author{
Prof. Dr. Claudio Alberto Gabriel Guimarães ${ }^{1}$ \\ Lícia Haickel Rosa²
}

Resumo: Objetiva-se, com o presente trabalho, fomentar a discussão acerca da real efetividade dos princípios reitores do Direito Penal quando da sua aplicação ao caso concreto em conexão com o Estado Democrático de Direito. A referida discussão perpassa necessariamente pelos fundamentos e pela legitimação do direito de punir, com ênfase no Estado Democrático, buscando-se uma contextualização atualizada. Analisa-se, a partir da criminologia crítica, o desvio social, o processo de criminalização e os mecanismos de rotulação de criminosos, tendo como base a desigual aplicação dos Princípios Constitucionais Penais. Importante destacar que a presente reflexão objetiva impulsionar debates e questionamentos sobre a desigualdade social proveniente dos conflitos de classe, sob a ótica da utilização do Direito Penal com fim de reprimir e estigmatizar as classes sociais menos favorecidas como meio de manutenção de privilégios e, consequentemente, do status quo.

Palavras-chave: direito de punir; estado democrático; exclusão social; princípios constitucionais.

Abstract: The purpose of this work is to foster discussion regarding the effectiveness of the guiding principles of criminal law when applied to real cases and in connection with the democratic rule of law. Such discussion inevitably permeates the grounds and the legitimacy of the right to punish,

1 Promotor de Justiça do Estado do Maranhão. Coordenador Estadual da Associação Brasileira de Professores de Ciências Penais - ABPCP. Sócio Fundador do Instituto Panamericano de Política Criminal. Especialista em Direito, Estado e Sociedade pela Universidade Federal de Santa Catarina. Especialista em Docência Superior pelo Centro Universitário do Maranhão - UNICEUMA. Mestre em Direito Público pela Universidade Federal de Pernambuco. Doutor em Direito Público pela Universidade Federal de Pernambuco, com área de concentração em Direito Penal. Doutor em Direito pela Universidade Federal de Santa Catarina, com área de concentração em Criminologia. Professor Pesquisador do CNPq, UNICEUMA e FACEMA. Professor na Universidade CEUMA e UFMA. E-mail: calguimaraes@yahoo.com.br.

2 Acadêmica do Curso de Graduação em Direito do UNICEUMA. Cursando $9^{\circ}$ período no Renascença. Bolsista PIBIC e integrante do NEVIC do CEUMA em 2014. Integrante do grupo de pesquisa da OAB em Direito Constitucional em 2015. E-mail: liciahr@hotmail.com 
emphasizing the democratic state, while seeking an updated context. Based on the study of critical criminology, social deviance, the process of marginalization, and labeling mechanisms of criminals an analysis of the unequal application of penal constitutional principles is performed. Importantly, the current work aims to increase debate and questioning regarding social inequality arising from class conflict under the guise of the use of criminal law in order to repress and stigmatize the underprivileged social classes while consequently maintaining the status quo.

Key Words: right to punish; democratic state; social exclusion; constitutional principles.

\section{Introdução}

O presente estudo objetiva, conforme a doutrina crítica majoritária, analisar a real aplicabilidade dos princípios reitores do Direito Penal, partindo-se do pressuposto de que o crime é o reflexo do conflito das classes sociais antagônicas, determinando os interesses da seleção dos fatos sociais e oficialmente catalogados como desviados.

O tema é importante para a sociedade, para a comunidade acadêmica e para os profissionais da área de Direito, pois a reflexão crítica traz a reboque novas formas de percepção dos fenômenos sociais, requisito básico para avançar no campo das ideias e, consequentemente, na concretização de avanços e mudanças no âmbito comunitário.

A questão da não efetividade da lei no Estado Democrático de Direito perpassa pela percepção de que a finalidade das normas jurídicas de assegurar a paz, a segurança e a possibilidade de convivência harmônica social, encontra-se somente, segundo as teorias aqui adotadas, na esfera do porvir.

Portanto, a pretensão final do estudo é descortinar outras percepções sobre o fenômeno punitivo, haja vista que o tema abordado comporta algo muito maior que apenas a teoria oficialmente aceita no meio jurídico, sendo necessário investigar o funcionamento do direito de punir do Estado, suas lacunas, possíveis acertos, mas, antes de tudo, cremos estar contribuindo para uma ampla discussão na comunidade acadêmica e sociedade sobre tão urgente temática.

\section{Material e Métodos}

A abordagem do tema foi realizada a partir do método dedutivo, por se tratar de uma pesquisa no campo teórico e interpretativo da realidade, no sentido de auxiliar a reflexão e a discussão a partir de um diferencial 
teórico capaz de identificar as essenciais críticas aos princípios reitores do Direito Penal. O método utilizado foi o monográfico, tendo como técnica de pesquisa a revisão bibliográfica, com utilização de sistemas de fichas de leitura e discussões preliminares. Foram analisados artigos científicos e obras, tendo como marco principal a tese adotada por Alessandro Baratta ${ }^{3}$.

\section{Resultados e Discussão}

\section{O Estado Democrático de Direito e o direito de punir}

O artigo $1^{\circ}$ da Carta Magna de 1988 declara que a República Federativa do Brasil constitui-se em Estado democrático de direito e está pautado nos ideais de soberania, cidadania, dignidade da pessoa humana, nos valores sociais do trabalho e da livre iniciativa e no pluralismo político, todos conferindo efetiva participação da sociedade no trato da coisa pública. $\mathrm{O}$ conceito de Estado democrático de direito tem como intuito garantir o respeito pelos direitos humanos e pelas garantias fundamentais, mediante o estabelecimento de uma proteção jurídica. O seu ponto de orientação deverá ser a defesa, implementação e manutenção da democracia, cuja consequência será o exercício da cidadania.

A questão da democracia na atualidade do Brasil é de se observar que não existe um liame entre o sistema penal e a aplicação das suas leis com o Estado Democrático de Direito, mediante as inúmeras dificuldades no contexto político, econômico e social nos quais estão submetidos para que ocorra sua real efetivação.

\section{Legitimação e fundamentação do direito de punir}

O Estado possui, verdadeiramente, o seu direito de punir a partir do momento em que utiliza os princípios constitucionais que norteiam a aplicação da lei penal, na sua fundamentação e legitimação para a devida clareza e igualitária aplicação da norma. O que se observa é uma desigual aplicação do Direito Penal, em que o status de criminoso encontra-se distribuído de forma desigual, ou seja, as prisões estão, na sua grande maioria, ocupadas pelo setor social menos favorecido. Assim, a efetividade do processo nas condutas ou ações qualificadas como tais passam a ser questionadas.

Desta forma, a mudança de paradigmas desloca-se e redefine a criminologia de um saber auxiliar do Direito Penal e interno, com a criminologia comportamental e da violência individual ao modelo integrado, crítico e externo, da violência institucional, que nos ensina que não se pode

3 Barros Filho (2013) destaca que: “...em relação ao crime e à criminalidade, a criminologia positivista fundamentou uma nova política criminal na qual os criminosos são vistos como inimigos da sociedade que devem ser eliminados." 


\section{1

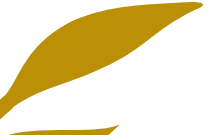

compreender o crime, a criminalidade e os criminosos sem compreender o controle social e penal que os constrói como tais, e esta culmina numa criminologia da violência estrutural, que nos ensina a compreendê-los não apenas a partir da mecânica do controle, mas funcionalmente relacionada às estruturas sociais (o capitalismo, o patriarcado, $\mathrm{O}$ racismo, etc). $\mathrm{A}$ seletividade do sistema penal é revelada, assim, como classista, sexista e racista, que expressa e reproduz as desigualdades, opressões e assimetrias sociais (ANDRADE, 2008, p.22-23).

\section{Direito Penal no Século XXI}

O desafio do Direito Penal no Século $X X I^{4}$ tem como destaque a influência que a mídia exerce na construção de um direito penal seletivo, em detrimento da ineficaz atuação do Estado quanto ao combate das desigualdades sociais e o poder punitivo. A imprensa utiliza-se de meios para ocultar a política de perseguição aos segmentos excluídos da sociedade, sendo estes setores vulneráveis e inaptos à sociedade de consumo. Exerce, ainda, um papel de dominação e disseminação da insegurança como um todo, que tem como consequência o clamor pela coerção estatal, o imediatismo punitivo ${ }^{5}$, para com a classe menos favorecida. Alguns programas e notícias propagados pela mídia acabam sendo benevolentes com a seletividade penal e com a criminalização da classe pobre.

Desta forma, os meios de comunicação são vistos como uma moderna ferramenta de dominação social, uma vez que inconscientemente impõe o que a população deve pensar e como reagir, criando um imaginário social da criminalização da pobreza e a necessidade de um Estado policial, em que a pena privativa de liberdade é vista como a única alternativa para o crime.

Atualmente, uma grande parte da doutrina adere ao posicionamento de duas grandes correntes teóricas acerca do controle social e trazem uma nova denominação para ambos: o realismo de direita, outrora ideologia da defesa social e o realismo de esquerda, vinculado às teorias críticas ou do conflito. A Ideologia da Defesa Social transmite a ideia de um estado ideal, em que tudo parece se encaixar de modo perfeito e cujos personagens

$4 \quad$ Andrade (2008) menciona que: “(...) A disciplina criminologia ocupa pouco espaço no ensino jurídico atual e as criminologias críticas pouco espaço na criminologia, sendo elas importantes para o mundo acadêmico. Ensinar criminologias é criar uma consciência jurídica crítica e responsável, capaz de transgredir as fronteiras da zona de conforto do penalismo adormecido na labuta técnico-jurídica; capaz de inventar novos caminhos para o enfrentamento das violências (individual, institucional e estrutural)."

$5 \quad$ Morselli (1997) destaca que: "...diante de um delito, surge na sociedade uma profunda exigência de represália, voltada a desencadear sobre o réu as cargas agressivas suscitadas pela frustração derivada do alarme social ou seletivo". 
nunca se afastam do que seja desejado, deixando apenas para uma minoria, os desviados, tal tipo de violação (GUIMARÃES, 2013).

\section{Princípios Constitucionais Penais}

Com base nas discussões sobre o controle social, o posicionamento da corrente teórica do realismo de direita, outrora ideologia da defesa social ou do "fim", com o objetivo de explicar a criminalidade, sustenta-se em seis princípios basilares, sendo eles: princípio da legitimidade, princípio do bem e do mal, da culpabilidade, da finalidade ou da prevenção, do interesse social e delito natural e o da igualdade. Tal ideologia nasceu contemporaneamente à revolução burguesa, sendo o liame entre a Escola Clássica e a Positiva do Direito Penal (BARATTA, 2011, p.42).

De acordo com o princípio da legitimidade, o Estado é o ente que detém o poder legítimo ${ }^{6}$ para atuar no sistema penal, coibindo a criminalidade em conformidade com a lei e tendo como objetivo reafirmar os valores e as normas sociais. Suas instâncias oficiais de controle social são: Poder Legislativo, Polícia, Ministério Público, Magistratura e Instituições Penitenciarias.

Os dois princípios opostos do Bem e do Mal têm como base o dualismo do filósofo grego Maniqueu, que dividia o mundo entre o Bom, ou o Deus, e o Mau ou o Diabo. Desta forma, o delito e o delinquente seriam a reprodução do mal e causadores do dano para a sociedade. O intuito é a existência de um controle do mal, ou seja, da criminalidade, a favor do bem, da sociedade. Assim é visto o princípio do bem e do mal.

Conforme o princípio da culpabilidade, o ato desviante é uma atitude previamente reprovável pela sociedade, pois contraria os valores e as normas estabelecidas, independentes se positivadas ou ainda não, pelo legislador. A atitude interior do autor do delito é consciente de que a sua ação é contrária à sociedade.

O princípio da finalidade ou da prevenção está intimamente relacionado às teorias da pena, englobando as funções de retribuição e prevenção do crime, uma vez que, ao ser violado o preceito primário, aplicar-se-á o preceito secundário cabível como forma de sanção penal. Desta forma, servirá de contramotivação ao comportamento criminoso diante da sua intimidação (prevenção geral negativa), sendo considerada

6 Bobbio (1995), sobre legitimidade do Estado, conceitua que: “... é uma situação nunca plenamente concretizada na história, a não ser como aspiração, e que um Estado será mais ou menos legítimo na medida em que tornar ela o valor de um consenso livremente manifestado por parte de uma comunidade de homens autônomos e conscientes, isto é, na medida em que consegue se aproximar à idéia-limite da eliminação do poder e da ideologia nas relações sociais." 


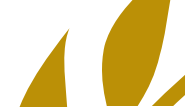

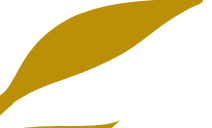

uma sanção abstrata, enquanto a reinserção (prevenção especial positiva) do infrator no meio social será a concreta.

Para o princípio do interesse social e do delito natural, os delitos naturais são aqueles tipificados no código penal, previamente conhecidos e reprovados pela sociedade, uma vez que representam ofensas aos interesses fundamentais essenciais e, consequentemente, à sua harmônica existência. Portanto, as leis penais dos Estados civilizados protegem os interesses comuns de todos os cidadãos. Em contrapartida, os delitos artificiais estão representados em uma pequena parcela dos fatos puníveis, sendo eles os de violação dos arranjos políticos e econômicos, de acordo com interesses segmentados.

E, por fim, para o princípio da igualdade, a legitimação do Direito Penal e, consequentemente, a sua fundamentação, tem como base os princípios da legalidade e da igualdade ${ }^{7}$, sendo o principal objetivo deste a aplicação igualitária das decisões judiciais, provendo a sociedade de segurança jurídica. Segundo tal princípio, a lei penal, quando violada por uma minoria desviante e, consequentemente, gerando o ato criminoso, será igualmente aplicada, de forma a ser observada a neutralidade e a imparcialidade da legislação perante o autor do delito.

\section{Crítica aos Princípios Constitucionais Penais}

Os princípios constitucionais penais existentes na ideologia da defesa social, quando analisados pelas teorias sociológicas contemporâneas, deparam-se com elementos críticos inerentes a cada um dos seis já citados, no que se refere à criminalidade. Estas teorias, denominadas teorias "liberais", estão inseridas, em especial, no campo da sociologia criminal burguesa e distinguem-se da criminologia "crítica", de inspiração marxista e das teorias liberais clássicas dos séculos precedentes, que se caracterizam, por uma atitude racionalista, reformista e, geralmente, progressista (BARATTA, 2011, p.49-126):

a) Negação do Princípio de Legitimidade: é representada pelas teorias psicanalíticas da sociedade punitiva, com raízes na doutrina freudiana da neurose e na sua aplicação, no que se refere à explicação do comportamento criminoso. Tais teorias colocam em dúvida a legitimação do direito de punir, visto que a reação penal ao comportamento delitivo

$7 \quad$ Grinover (2008) sobre o princípio da igualdade destaca que: “... a aparente quebra do princípio da isonomia, dentro e fora do processo, obedece exatamente ao princípio da igualdade real e proporcional, que impõe tratamento desigual aos desiguais, justamente para que, supridas as diferenças, se atinja a igualdade substancial. Lembre-se, ainda, que no processo penal o princípio da igualdade é atenuado pelo favor rei". 
não tem o intuito de restringir ou elidir a criminalidade, mas equivale a mecanismos psicológicos em face dos quais o desvio criminalizado aparece como necessário e ineliminável do meio social.

A punição representa uma defesa e um reforço do superego, dando ênfase aos mecanismos sociopsicológicos, pois no delinquente irá contrabalançar a pressão dos impulsos reprimidos. A sociedade punitiva, separando-se do sujeito delinquente, como o bem do mal, transfere para ele as próprias agressões.

Portanto, a negação baseia-se no fato de que o comportamento delituoso está inserido no mecanismo psicossocial e, desta forma, não tem o intuito de negar os valores e as normas legitimadas pelo meio social, mas visa manter a sociedade de forma coesa, negando a si própria a sua identificação com o criminoso ao punir.

b) Negação do Princípio do Bem e do Mal: é proveniente da teoria estrutural-funcionalista da anomia $^{8}$ e da criminalidade, sendo posterior às teorias psicanalíticas e representando a virada em direção sociológica efetuada pela criminologia contemporânea.

Sob o prisma desta teoria, o crime faz parte, enquanto elemento funcional, da fisiologia e não da patologia da vida social, sendo visto como um comportamento natural e necessário na formação da sociedade, um fenômeno "normal" para o desenvolvimento estrutural da vida social quando ocorrer dentro de determinados limites quantitativos e qualitativos. Entretanto, será negativo se ultrapassar tais limites das funções psicossociais, sendo considerado um obstáculo para a existência e o desenvolvimento social. Assim, não serão aceitas elevadas discrepâncias entre as normas e os fins culturais, ou seja, o nível crítico da anomia.

O paradoxo desta teoria fundamenta-se na normalidade do delito, que irá provocar e estimular a reação social, estabilizando o sentimento coletivo e sustentando a aceitação às normas pela sociedade; além da funcionalidade do delito, sendo este visto como a antecipação da moral futura.

c) Negação do Princípio da Culpabilidade: é proveniente da teoria das subculturas criminais, tendo na desconformidade com relação às normas sociais o seu ponto inicial. A reação de minorias desfavorecidas e a sua tentativa de se adequarem no meio social, não obstante as reduzidas possibilidades legítimas de agir, de que dispõem, constituem as subculturas

8 Schecaira (2013, p.314) evidencia que a teoria da anomia contribuiu para o direito penal na concepção de pena funcional, tendo as seguintes manifestações: como meio de intimidação individual se dirige ao delinquente ocasional; como instrumento de reinserção social, ao delinquente habitual corrigível; e, como mecanismo de neutralização, ao delinquente incorrigível. 


\section{(

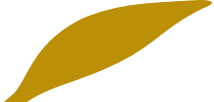

criminais ${ }^{9}$.

A teoria das subculturas criminais nega que o delito seja proveniente de uma atitude contrária aos valores e normas sociais gerais, pois considera que a sociedade é dividida por diversos grupos ou subculturas com valores e normas específicas. Por intermédio de mecanismos de interação e de aprendizagem, no interior destes grupos, são determinados os códigos de valores, sendo pautada a conduta de todos os seus componentes e a assimilação, inclusive as delituosas. Assim, o comportamento criminoso está relacionado ao código de valores pertencente àquela subcultura e aos seus integrantes. Portanto, o peso específico da escolha individual ou da determinação da vontade, como também o dos caracteres naturais da personalidade, é muito relativo.

d) Negação do Princípio do Fim ou da Prevenção: a pesquisa dos teóricos do labeling approach é constituída de dois campos de investigação: o estudo da formação da identidade desviante e seus efeitos como o desvio secundário ou aplicação da etiqueta de criminoso ou de doente mental realizado pelas agências oficiais; e a busca por definição da constituição do desvio e pela distribuição do seu poder, ou seja, o estudo das agências de controle social.

$\mathrm{Na}$ corrente da identidade e das carreiras desviantes ${ }^{10}$, a primeira direção da pesquisa se deteve, em especial, sobre os efeitos da estigmatização na formação do status social de desviante, tendo como consequência da aplicação da sanção, uma decisiva mudança na identidade social do indivíduo.

Da relação entre a criminologia liberal contemporânea e a ideologia penal, destacam-se os resultados da pesquisa na criminologia inspirada no labeling approach sobre o desvio secundário e sobre carreiras criminosas, pondo em dúvida o princípio do fim ou da prevenção e, em especial, a concepção reeducativa da pena. A identidade desviante proveniente do processo de criminalização, em especial nas penas detentivas, será constante na vida social do sujeito autor do crime, não existindo a possibilidade de reeducação deste, mas com grandes oportunidades de continuidade na vida do crime.

9 Andrade (1997, p.205) sobre a negação do princípio da culpabilidade destaca que: “... transcende o poder de decisão do indivíduo e, portanto, sua responsabilidade moral, o fato de participar ou não de uma determinada subcultura e, em consequência, de aprender um determinado sistema de valores ou ainda determinados comportamentos desviantes ou "técnica de neutralização" alternativas aos critérios oficiais de comportamento e de valoração."

10 Schecaira (2013, p.315) conclui que o delinquente apenas se distingue do homem normal devido à estigmatização que sofre, particularmente aquela decorrente do recolhimento às chamadas instituições totais, em especial a prisão. 
e) Negação do Princípio da Igualdade: a sociologia ${ }^{11}$ criminal e moderna tiveram como ponto de partida os mecanismos de reação e de seleção da população criminosa, com os seguintes campos de investigação: a criminalidade do colarinho branco de Sutherland, a cifra negra da criminalidade e a crítica das estatísticas criminais oficiais.

Com a análise dos dados estatísticos da distribuição da criminalidade nos estratos sociais, tendo concentração nos menos favorecidos, observase uma distorção nas teorias da criminalidade relacionadas com estas interpretações, uma vez que tais valores são baseados sobre o que é identificado na criminalidade enquanto o crime de colarinho branco é representado de modo consideravelmente inferior à sua calculável "cifra negra". Desta forma, tem-se um quadro falso da distribuição da criminalidade nos grupos sociais, com incidência sobre o seu estereótipo e que influenciam em uma ação seletiva dos órgãos oficiais no meio social.

Tal pesquisa refere-se, no geral, à real frequência e à distribuição do comportamento desviante penalmente perseguível em determinada sociedade. $\mathrm{E}$ tem o intuito de demonstrar que a criminalidade não está ligada ao comportamento de uma restrita minoria, mas de largos estratos sociais.

A criminalidade como realidade social é uma qualidade instituída pelos juízes ou tribunal a determinados indivíduos através de sentenças que alteram o status quo do imputado. Desta forma, a criminalidade não existe na natureza, mas é uma realidade construída socialmente através de processos de definição e de interação. A seleção da população carcerária ${ }^{12}$, tendo como análise a perspectiva macrossociológica da interação e das relações de poder entre os grupos sociais, tem como maioria, nos países da área do capitalismo avançado, o público-alvo das classes economicamente mais débeis. Assim, observa-se o mecanismo de antagonismo e de poder com desigual distribuição de bens e de oportunidades entre os indivíduos como possível gerador de tais fenômenos.

Apesar de inúmeras críticas, observa-se que as teorias da criminalidade com base no labeling approach conduziram a resultados irreversíveis que abalaram os fundamentos da ideologia tradicional. O princípio da igualdade foi colocado em discussão e, segundo a sua

11 Andrade (1997, p.201) sobre a negação do princípio da igualdade menciona que: “...segundo a definição sociológica, a criminalidade, como em geral do desvio, é um status social que caracteriza ao indivíduo somente quando lhe é adjudicada com êxito uma etiqueta de desviante ou criminoso pelas instâncias que detêm o poder de definição."

12 Schecaira (2013, p.119) menciona como erro dos positivistas que: “...os mecanismos seletivos já tinham atuado, exercendo seu papel de seleção da clientela que viria a ser identificada com algumas características pessoais, quando estas já foram determinantes para a seleção pelo sistema punitivo." 


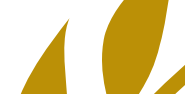

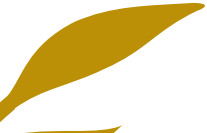

definição sociológica, o status recebe atribuição de grupos de poder que, além de criar e aplicar a lei penal, ainda utiliza-se de mecanismos seletivos, onde a estratificação e o antagonismo dos grupos sociais possuem uma influência fundamental. Tal ideologia estende-se aos demais princípios como: legitimidade, interesse social e delito natural.

A teoria do labeling aproach nega o princípio da igualdade, uma vez que, apesar de comportamentos passíveis de criminalização não estarem restritos a grupos sociais específicos, mas a todos os setores sociais, observa-se que existe uma parcela deste grupo que não é apreendida pelo sistema punitivo.

f) Negação do Princípio do Interesse Social e do Delito Natural: com base nos interesses protegidos pelo Direito Penal a serem considerados comuns a toda sociedade, este princípio ${ }^{13}$ irá representar violação e punição de determinados arranjos políticos e econômicos apenas a uma pequena parte dos delitos. Desta forma, a negação a tal princípio ocorre pela teoria da reação social ou do etiquetamento (labeling approach), em que o desvio, com a sua qualidade criminosa, é visto como uma realidade construída mediante as definições e as reações sociais, sendo a criminalidade um status social atribuído através de processos (informais e formais) de definição e mecanismos (informais e formais) de reação.

As teorias conflituais da criminalidade, com uma perspectiva macrossociológica, negam o princípio do interesse social e do delito natural, pois afirmam que os interesses comuns a todos os cidadãos não são os protegidos pelo Direito Penal e a realidade social é criada pelo processo de criminalização. Desta forma, a criminalidade e todo o Direito Penal terão sempre natureza política. Esta teoria parte de uma teoria geral da sociedade, onde o modelo de conflito é fundamental e o objeto de sua polêmica era a teoria estrutural-funcionalista, então dominante na sociologia liberal, pois estudavam os sistemas sociais sob o ponto de vista de sua estabilização e conservação, negando a objetividade dos contrastes de classe. As críticas do estrutural-funcionalismo tornam-se um tema central tanto para a sociologia alternativa de inspiração marxista quanto para a sociologia liberal, em especial, na metade dos anos 50 , quando iniciam as mudanças nas condições político-econômicas.

Neste sentindo, o crime é visto como um comportamento político e o criminoso como um membro de um grupo minoritário sem a base pública

13 Andrade (1997, p.202) sobre a negação deste princípio destaca que: “...na origem do processo de criminalização primária (gênese da lei penal) e secundária (aplicação da lei penal) não residem interesses fundamentais para uma determinada sociedade ou diretamente para toda sociedade civilizada, mas interesses dos quais são portadores os grupos que detêm o poder." 
suficiente para dominar e controlar o poder de polícia do Estado. O conflito ocorre quando há a concorrência entre os grupos, de forma a eliminarem-se reciprocamente.

\section{Conclusão}

O estudo da punição, no âmbito do Estado Democrático de Direito, deve ser realizado através da análise dos princípios constitucionais que norteiam o Direito Penal, sob as seguintes perspectivas: a reflexão sobre os fundamentos e a legitimação do direito de punir, sobre o conteúdo teórico dos princípios constitucionais penais em confronto com sua aplicabilidade concreta e, consequentemente, sobre as críticas a estes referentes.

Os princípios constitucionais reitores do Direito Penal não possuem sua efetiva aplicabilidade devido ao fato do hodierno Estado Democrático de Direito ser um instrumento de controle social utilizado pelos detentores do poder com o objetivo único de se manterem no controle das esferas política e econômica.

De acordo com esta pesquisa, o perfil do preso nas sociedades do capitalismo avançado configura-se por aqueles que estão fora da sociedade de consumo, uma vez que nos encontramos em uma sociedade fortemente influenciada por um sistema globalizado, pela força persuasiva da mídia que, ao impor seus interesses econômicos, provoca um desequilíbrio social, deixando para o controle penal a responsabilidade para resolver tal questão.

Dessume-se, portanto, diante dos aspectos apresentados, que muitas são as complicações acerca da realidade prática em que se insere o Direito Penal. As desigualdades sociais visualizadas geram uma série de desvios na aplicação das leis punitivas, a maioria deles sendo relacionados com a rotulação de criminosos e a seletividade nas punições aplicadas.

Por fim, importante ressaltar que tais dificuldades não invalidam a real importância do estudo e da discussão sobre os aspectos inerentes ao tema proposto, haja vista que tal discussão é fundamental para que ocorra a real efetivação dos Princípios Constitucionais concernentes ao Direito Penal na prática criminal, bem como para que se estimule a criação de políticas públicas maciças direcionadas à mudança da realidade, visando a abolição das desigualdades sociais geradoras das arbitrariedades no sistema penal hodierno e traçando diretrizes que tornem efetivos os princípios constitucionais regentes do direito de punir e conduzam à aplicação justa, proporcional e igualitária da legislação penal. 


\section{REFERÊNCIAS}

ANDRADE, Vera Regina Pereira de. A ilusão de segurança jurídica: do controle da violência à violência do controle penal. Porto Alegre: Livraria do advogado, 1997.336p.

BARATTA, Alessandro. Criminologia Crítica e crítica ao direito penal: introdução à sociologia do Direito Penal. Tradução Juarez Cirino dos Santos. 6.ed. Rio de Janeiro: Editora Revan: Instituto Carioca de Criminologia, 2011. 254p.

BOBBIO, Norberto. Dicionário de política. v.2, 13.ed. Editora UNB, 2010. 1318p.

Estado, governo, sociedade: para uma teoria geral da política. 12.ed.São Paulo: Paz e Terra, 2005. 167p.

GRINOVER, Ada Pellegrini. et al. Teoria Geral do Processo. 24 ed.rev., atual. São Paulo: Editora Malheiros, 2008, 384p.

GUIMARÃES, Claudio Alberto Gabriel. Constituição, Ministério Público e Direito Penal. A defesa do Estado Democrático no âmbito Punitivo. Rio de Janeiro: Revan, 2010, 286p.

. Funções da pena privativa de liberdade no sistema penal capitalista. 2 ed. Rio de Janeiro: Revan, 2007, 350p.

- Reflexões acerca do controle social formal: rediscutindo os fundamentos do direito de punir. Jun. de 2013. Disponível em: <http://www.epublicacoes.uerj.br/index.php/rfduerj/article/view/4894.> Acesso $18 \mathrm{dez}$. de 2013. Revista da Faculdade de Direito da UERJ. Rio de Janeiro, v.1, n.23 .

MORAES, Alexandre de. Direito Constitucional. 28 ed.São Paulo: Atlas, 2012.

MORSELLI, Élio. A função da pena à luz da moderna criminologia. Revista Brasileira de Ciências criminais. São Paulo, ano 5, n.19, p-39-46, jul./set. 1997.

SCHECAIRA, Sérgio Salomão. Criminologia. 5.ed. ver. São Paulo: Editora Revista dos Tribunais, 2013, 336p.

ZAFFARONI, Eugenio Raúl. et al. Manual de Direito Penal Brasileiro: parte Geral. 10 ed.rev., atual.São Paulo: Editora Revista dos Tribunais, 2013, 796p. 